\title{
Estimation of Natural Gas Production, Import and Consumption in Brazil Based on Three Mathematical Models
}

\author{
Antonio Carlos Gracias ${ }^{1,2 *}$, Sérgio Ricardo Lourenço ${ }^{1}$, Marat Rafikov ${ }^{1}$ \\ ${ }^{1}$ Engineering, Modeling and Applied Social Sciences Center (CECS), Federal University of ABC, Santo André, Brazil; ${ }^{2}$ Department \\ of Mathematics, University Center of FEI, São Bernardo do Campo, Brazil. \\ Email: "antonio.gracias@ufabc.edu.br
}

Received January $6^{\text {th }}, 2012$; revised March $2^{\text {nd }}, 2012$; accepted March $10^{\text {th }}, 2012$

\begin{abstract}
A mathematical model capable of providing a forecast of future consumption and import of natural gas is essential for the planning of the Brazilian energy matrix. The aim of this study is to compare three mathematical models, logistic model or model of Verhulst, exponential model or the model of Malthus and the model of von Bertalanffy to analyze the possibilities of these models to describe the evolution of production, import and consumption of natural gas in Brazil, from data provided by the energy balance of the Ministry of Mines and Energy (MME) from 1970 to 2009. A projection of the production and the import of natural gas up to 2017 is made with the models studied in this article and compared with the Brazilian Ten-Year Plan for Expansion of Energy (PDE). At the end of this paper a comparison with the Hubbert model for Brazilian natural gas production is made. These data were adjusted to use the differential equations which describe the models of population growth. All the computer work used in this article: graphics, resolution of differential equations, calculations of linearization and the least squares fitting was prepared in the software MatLab. The results obtained by means of graphs show that the population dynamics models (logistic, exponential and von Bertalanffy) can be applied in modeling the production, import and consumption of natural gas in Brazil.
\end{abstract}

Keywords: Natural Gas; Mathematical Modeling; Logistic Model; Exponential Model; Model of Von Bertalanffy

\section{Introduction}

The federal government, through a policy of development, aims to extend the participation of natural gas in the energy matrix from $2 \%$ to $12 \%$ in the next ten years [1]. A mathematical model capable of providing a forecast of future consumption and import of natural gas is essential for the planning of the Brazilian energy matrix.

The increase in supply of electric energy in Brazil will only occur with the generation of heat by natural gas. However, the Brazilian reserves of natural gas have two main characteristics: $80 \%$ is associated gas and $55 \%$ is located in deep water. In consequence, the supply of natural gas is influenced and very dependent on oil production.

World consumption of natural gas will increase at a rate of 2.3\% per year until 2025 [2]. This increase in global consumption will be felt also in Brazil, with the increasing participation of natural gas in the energy matrix, especially after the crisis in the electrical sector in 2001. The supply of natural gas has been dependent on Bolivia, since the end of the construction of the pipeline

*Corresponding author. in 1999. This dependence has reached 50\% in 2006 [3], which led to supply problems due to the political crisis faced by Bolivia in 2006. These problems caused a crisis in supply of gas in Brazil, which led Petróleo Brasileiro (PETROBRAS) to review the dependencies on Bolivian gas aiming to reduce the dependence to the maximum of 22\% until 2016 [3].

Around the world, the use of natural gas is growing both in industry and in transport and the generation of electricity with the use of thermoelectric power plants for a number of reasons, including price, environmental concerns, fuel diversification, issues security, deregulation and economic growth worldwide marketing. Studies show the relationship between natural gas consumption and economic growth [4].

\section{Description of the Models}

The dynamics of populations [5] deals with changes in time and space the densities and sizes of populations. The study of population dynamics is not restricted only to the understanding of the variation in the number of 
individuals of a given population, but also in the study of biological control of pests [6], the growth strategies of animals [7] strategies and growth of cities. The models dealing with population growth are the models logistic, exponential and von Bertalanffy. The application of these models in the study of production and import of natural gas is possible because the data presented in Tables 1 and $\mathbf{2}$ show characteristics of population growth.

\subsection{Exponential Models}

The exponential model is the simplest model that describes the population growth of some species. It is represented by a differential equation of first order establishing the rate of change of population in relation to time. The differential equation for this model is:

$$
\frac{\mathrm{dN}}{\mathrm{dt}}=\mathrm{rN}
$$

where $\mathrm{dN} / \mathrm{dt}$ is the rate of the populational change and $\mathrm{r}$ is the rate of population growth $\mathrm{r}=(1+\alpha)$ and $\alpha$ is the rate population growth average $\alpha=\left(\mathrm{N}_{\mathrm{t}} / \mathrm{N}_{0}\right)^{1 / 2}-1 . \mathrm{N}_{\mathrm{t}}$ is the population after a period of $t$ years in relation to initial population $\mathrm{N}_{0}$.

The solution of the Equation (1) is:

$$
\mathrm{N}(\mathrm{t})=\mathrm{N}_{0} \mathrm{e}^{\mathrm{rt}}
$$

where $\mathrm{N}_{0}$ is the initial population.

\begin{tabular}{|c|c|c|c|}
\hline Year & Production $\left(10^{6} \mathrm{~m}^{3}\right)$ & Year & Production $\left(10^{6} \mathrm{~m}^{3}\right)$ \\
\hline 1970 & 1264 & 1990 & 6279 \\
\hline 1971 & 1178 & 1991 & 6597 \\
\hline 1972 & 1241 & 1992 & 6976 \\
\hline 1973 & 1180 & 1993 & 7355 \\
\hline 1974 & 1488 & 1994 & 7756 \\
\hline 1975 & 1625 & 1995 & 7955 \\
\hline 1976 & 1642 & 1996 & 9156 \\
\hline 1977 & 1808 & 1997 & 9825 \\
\hline 1978 & 1933 & 1998 & 10788 \\
\hline 1979 & 1899 & 1999 & 11898 \\
\hline 1980 & 2205 & 2000 & 13283 \\
\hline 1981 & 2475 & 2001 & 13998 \\
\hline 1982 & 3030 & 2002 & 15568 \\
\hline 1983 & 4013 & 2003 & 15792 \\
\hline 1984 & 4902 & 2004 & 16971 \\
\hline 1985 & 5467 & 2005 & 17699 \\
\hline 1986 & 5686 & 2006 & 17706 \\
\hline 1987 & 5781 & 2007 & 18152 \\
\hline 1988 & 6076 & 2008 & 21593 \\
\hline 1989 & 6105 & 2009 & 21142 \\
\hline
\end{tabular}

Table 1. Production of natural gas.

Source: MME, 2010.

\subsection{Logistic Model}

The logistic model assumes that a population will grow to a maximum limit, i.e., the population tends to stabilize. This stability of the population in the logistic model is related to the ability to support the way that people live. The differential equation for this model is:

$$
\frac{\mathrm{dN}}{\mathrm{dt}}=\mathrm{rN}\left(1-\frac{\mathrm{N}}{\mathrm{K}}\right)
$$

where $\mathrm{r}$ is the rate of population growth and $\mathrm{K}$ is the level of the population saturation.

The solution of the Equation (3) is obtained by the method of separable variables [8]:

$$
\mathrm{N}(\mathrm{t})=\frac{\mathrm{KN}_{0}}{\mathrm{~N}_{0}+\left(\mathrm{K}-\mathrm{N}_{0}\right) \mathrm{e}^{-\mathrm{rt}}}
$$

where $\mathrm{N}_{0}$ is the initial population.

The logistic model [9] was used to model annual and seasonal natural gas consumption for residential and commercial sectors in Iran. The logistics parameters were estimated using optimization techniques as NLP (nonlinear programming) and GA (genetic algorithm).

\subsection{Von Bertalanffy Model}

The von Bertalanffy model is the logistic model modified to model fish weight growth [10]. The differential equation for this model is:

$$
\frac{\mathrm{dN}}{\mathrm{dt}}=\mathrm{rN}^{2 / 3}\left[1-\left(\frac{\mathrm{N}}{\mathrm{K}}\right)^{1 / 3}\right]
$$

where $r$ is the rate of population growth and $K$ is the level of the population saturation.

The solution of the Equation (5) is obtained solving Bernoulli equation [8]:

$$
\mathrm{N}(\mathrm{t})=\mathrm{K}\left[1-\left[1-\left(\frac{\mathrm{N}_{0}}{\mathrm{~K}}\right)^{1 / 3}\right] \mathrm{e}^{-\left(\frac{\mathrm{rt}}{3 \mathrm{~K}^{1 / 3}}\right)}\right]^{3}
$$

where $\mathrm{N}_{0}$ is the initial population.

\subsection{Hubbert Model}

The Hubbert model was developed by $M$. K. Hubbert in 1956 to project the discoveries and production in US-48 in the USA [11]. The equation for the Hubbert model [12] for the annual production $\mathrm{P}$ is simple when related to the annual peak production Pm occurring at year tm:

$$
\mathrm{P}(\mathrm{t})=\frac{2 \mathrm{Pm}}{1+\cosh (-\mathrm{b}(\mathrm{t}-\mathrm{tm}))}
$$

where $\mathrm{b}$ is $5 / \mathrm{c}, \mathrm{P}$ is production in $\mathrm{t}, \mathrm{Pm}$ is production at peak, $\mathrm{tm}$ is the peak period and $\mathrm{c}$ is the duration of the half life from a cut-off at $0.027 \mathrm{Pm}$. 


\section{Methodology}

The study was conducted from data on production, import and consumption of natural gas from the energy balance of the Ministry of Mines and Energy [13] described in Tables 1-3. Table 1 presents data from the production, Table 2 presents data from the import and Table $\mathbf{3}$ presents data from the consumption of natural gas in Brazil.

To use the models applied to population dynamics in the production, import and consumption of natural gas the data were adjusted to use the differential equations which describe the models. Some parameters of the differential equations were linearized and others obtained by the least squares fitting.

\section{Results and Discussions}

The results for production, import and consumption of natural gas will be presented separately. In each set of data, production, import and consumption of natural gas, we applied the best model to describe the data. In the final section a comparison with the model used in the Ten Year Energy Plan (PDE) 2008-2019 [14] was made.

\subsection{Production of Natural Gas}

The results for the exponential model with the data of Table 1 are presented in Figure 1. For the exponential model to average growth rate of production $\alpha$ is given by:

$$
\alpha=(21142 / 1500)^{39}-1
$$

where: $\mathrm{N}_{0}=1500 \times 10^{6} \mathrm{~m}^{3}$ of gas.

\subsection{Import of Natural Gas}

Brazil began to import natural gas in 1999, therefore, there were few points to apply the von Bertalanffy model, as Table 2. The same procedure done for the production of natural gas was applied to the import of natural gas. For the von Bertalanffy model shown in Figure 2, the value of $\mathrm{K}$ used was $11,330 \times 10^{6} \mathrm{~m}^{3}$ of gas.

Table 2. Import of natural gas.

\begin{tabular}{cc}
\hline Year & Import $\left(10^{6} \mathrm{~m}^{3}\right)$ \\
\hline 1999 & 400 \\
2000 & 2.211 \\
2001 & 4608 \\
2002 & 5269 \\
2003 & 5055 \\
2004 & 8086 \\
2005 & 8998 \\
2006 & 9789 \\
2007 & 10334 \\
2008 & 11314 \\
2009 & 8543 \\
\hline
\end{tabular}

Source: MME, 2010.
Table 3. Consumption of natural gas.

\begin{tabular}{|c|c|c|c|c|c|}
\hline Year & $\begin{array}{c}\text { Energy } \\
\left(10^{6} \mathrm{~m}^{3}\right)\end{array}$ & $\begin{array}{l}\text { Industry } \\
\left(10^{6} \mathrm{~m}^{3}\right)\end{array}$ & $\begin{array}{c}\text { Home } \\
\left(10^{6} \mathrm{~m}^{3}\right)\end{array}$ & $\begin{array}{c}\text { Other } \\
\left(10^{6} \mathrm{~m}^{3}\right)\end{array}$ & $\begin{array}{c}\text { Total } \\
\left(10^{6} \mathrm{~m}^{3}\right)\end{array}$ \\
\hline 1970 & 74 & 3 & 0 & 3 & 80 \\
\hline 1971 & 93 & 12 & 0 & 21 & 126 \\
\hline 1972 & 100 & 22 & 0 & 51 & 173 \\
\hline 1973 & 98 & 23 & 0 & 77 & 198 \\
\hline 1974 & 137 & 163 & 0 & 81 & 381 \\
\hline 1975 & 149 & 173 & 0 & 92 & 414 \\
\hline 1976 & 146 & 183 & 0 & 148 & 477 \\
\hline 1977 & 160 & 312 & 0 & 123 & 595 \\
\hline 1978 & 156 & 294 & 0 & 333 & 783 \\
\hline 1979 & 161 & 311 & 0 & 386 & 858 \\
\hline 1980 & 188 & 363 & 0 & 452 & 1003 \\
\hline 1981 & 197 & 381 & 0 & 322 & 900 \\
\hline 1982 & 391 & 413 & 0 & 482 & 1286 \\
\hline 1983 & 489 & 449 & 0 & 801 & 1739 \\
\hline 1984 & 628 & 519 & 0 & 877 & 2024 \\
\hline 1985 & 911 & 680 & 0 & 948 & 2539 \\
\hline 1986 & 1050 & 871 & 0 & 1037 & 2958 \\
\hline 1987 & 1062 & 1131 & 1 & 1108 & 3302 \\
\hline 1988 & 935 & 1198 & 0 & 1191 & 3324 \\
\hline 1989 & 894 & 1246 & 0 & 1268 & 3408 \\
\hline 1990 & 859 & 1535 & 2 & 1018 & 3414 \\
\hline 1991 & 768 & 1617 & 5 & 1068 & 3458 \\
\hline 1992 & 840 & 1806 & 6 & 1043 & 3695 \\
\hline 1993 & 974 & 1947 & 6 & 1089 & 4016 \\
\hline 1994 & 1025 & 2025 & 20 & 1193 & 4263 \\
\hline 1995 & 989 & 2353 & 30 & 1063 & 4435 \\
\hline 1996 & 1199 & 2860 & 52 & 983 & 5094 \\
\hline 1997 & 1226 & 3194 & 72 & 916 & 5408 \\
\hline 1998 & 1471 & 3133 & 81 & 1054 & 5739 \\
\hline 1999 & 1696 & 3517 & 87 & 1015 & 6315 \\
\hline 2000 & 2278 & 4343 & 79 & 1265 & 7965 \\
\hline 2001 & 2419 & 5141 & 114 & 1576 & 9250 \\
\hline 2002 & 2722 & 6343 & 140 & 2067 & 11272 \\
\hline 2003 & 2938 & 6658 & 154 & 2438 & 12188 \\
\hline 2004 & 3168 & 7572 & 196 & 2729 & 13665 \\
\hline 2005 & 3500 & 8209 & 206 & 3129 & 15044 \\
\hline 2006 & 3712 & 8595 & 217 & 3556 & 16080 \\
\hline 2007 & 4013 & 9149 & 236 & 3841 & 17239 \\
\hline 2008 & 5227 & 9605 & 251 & 3469 & 18552 \\
\hline 2009 & 5414 & 8137 & 260 & 3118 & 16929 \\
\hline
\end{tabular}

Source: MME, 2010.

The Figure 2, shows that the import of gas tends to stabilize according to what was described by Santana et al. [3], especially with the reduction of dependence on Bolivian gas.

\subsection{Consumption of Natural Gas}

The natural gas consumption in Brazil is primarily Industrial as Figure 3. In 2007, industrial use accounted for $54 \%$ of the Brazilian natural gas demand [15]. The participation of home consumption in Brazil's energy matrix 
is very small when compared with countries such as Poland [16], Iran [9] and Turkey [17]. Aydinalp et al. [18] used neural network (NN) to model residential energy consumption in Canada.

For the logistic model shown in Figure 4, the terms $\mathrm{K}$ and $\mathrm{r}$ of Equation (4) were obtained by least squares fitting of the Equation (3). The value of $\mathrm{K}$ used was 50,000 $\times 10^{6} \mathrm{~m}^{3}$ of gas.

\subsection{Projection of Production and Import of Natural Gas by 2017 with the Use of Population Dynamics Models}

Table 4 represents the forecasted daily production and importation of natural gas in the PDE from 2008 to 2017. Total production (TP) is expected to increase year-onyear until 2010, reaching a level of $95 \mathrm{MMm}^{3} /$ day. It will

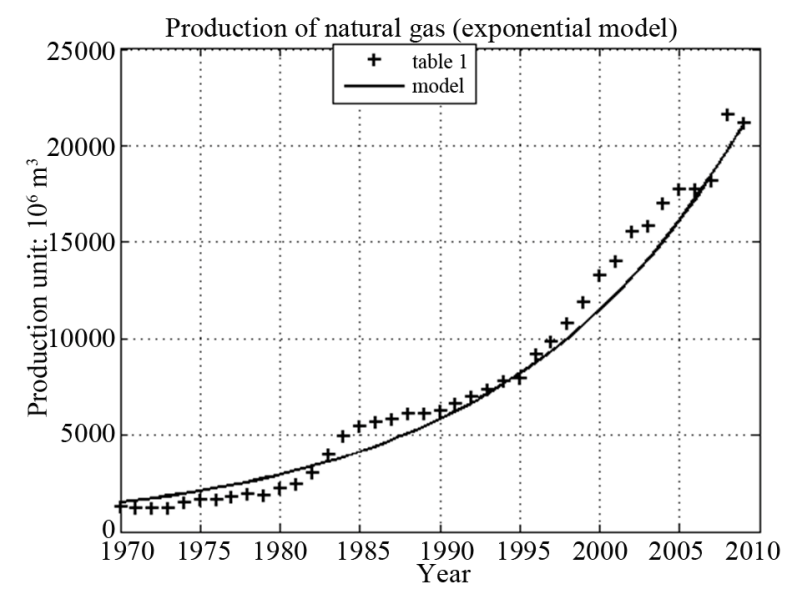

Figure 1. Production of natural gas as function of time with the exponential model. then stay at around that level until 2013, when it will begin a further period of increase until 2016. The importation of natural gas from Bolivia and Argentina is expected to stabilize at a level of $30 \mathrm{MMm}^{3} /$ day.

The Figure 5 shows the forecast of natural gas production until 2017 from exponential model. Comparing the results in Table 4 with the results of the exponential model, we found out that between 2009 and 2017 the points are near the projection.

The Figure 6 shows the forecast of natural gas import until 2017 from von Bertalanffy model. Comparing the results in Table 4 with the results of the von Bertalanffy model, it's possible to see that results are close to the projection. The results from the logistic model showed $30.9 \mathrm{MMm}^{3} /$ day in 2015 and the value of Table 4 for the same period was $30.1 \mathrm{MMm}^{3} /$ day.

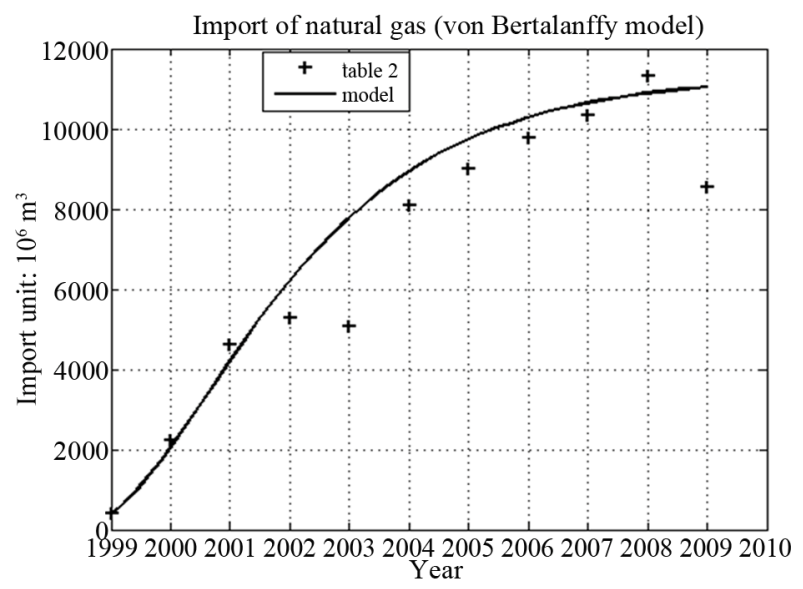

Figure 2. Import of natural gas as function of time with the von Bertalanffy model.

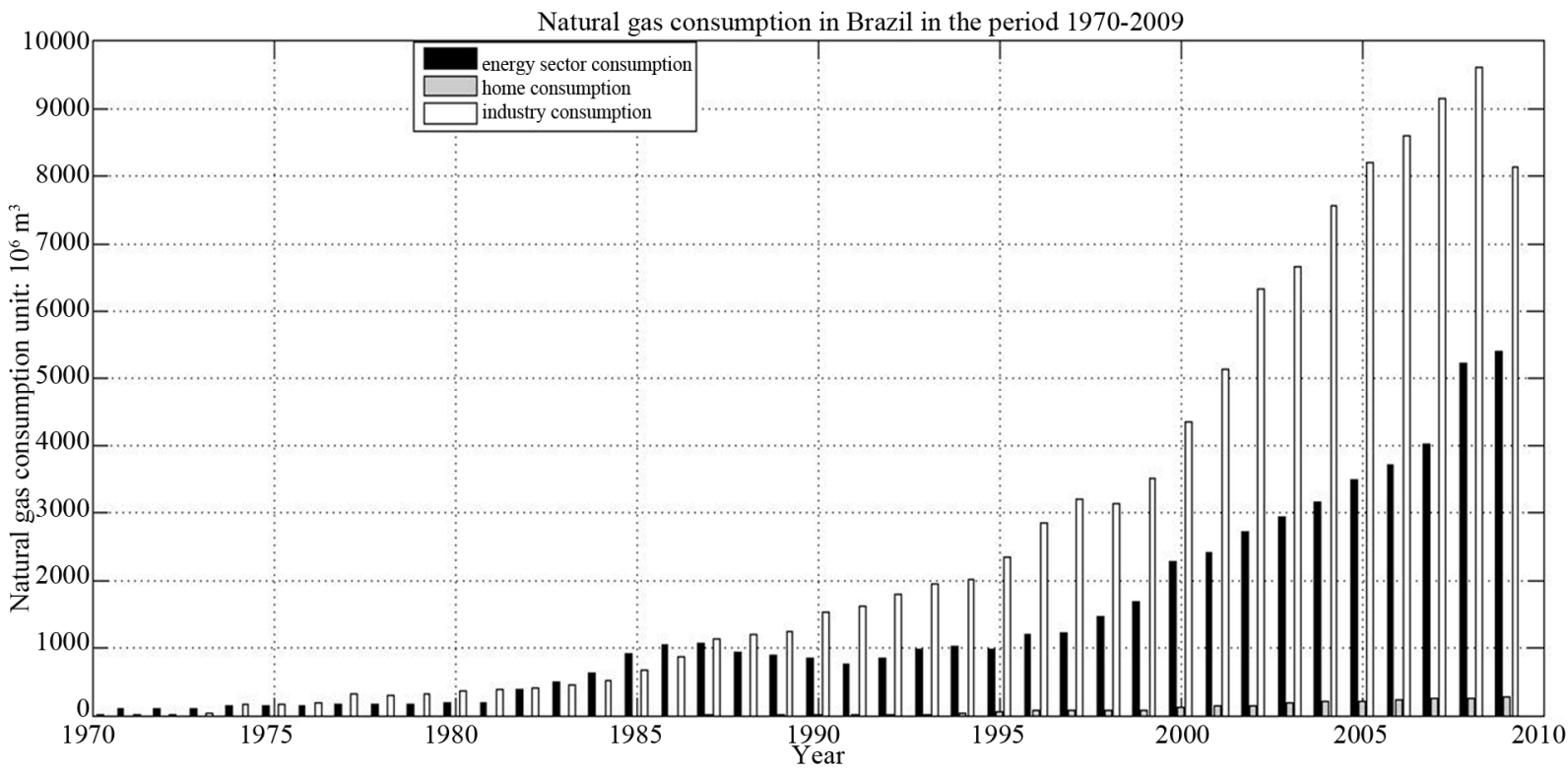

Figure 3. Consumption of natural gas in Brazil. 
The Figure 7 shows the Hubbert curve for Brazilian gas production together with the exponential model. Brazil's peak production was forecasted by the Hubbert curve to occur in 2022 at 32,380 $\mathrm{MMm}^{3}$.

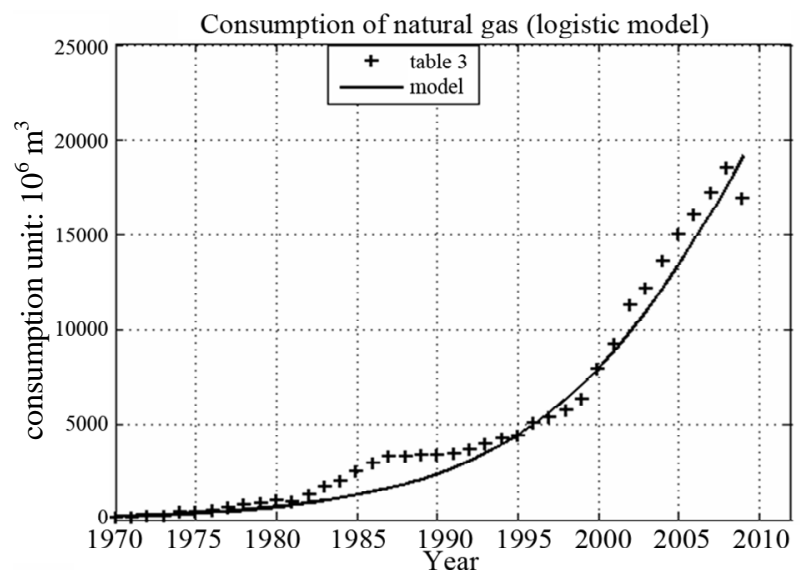

Figure 4. Total consumption of natural gas as function of time with the logistic model.

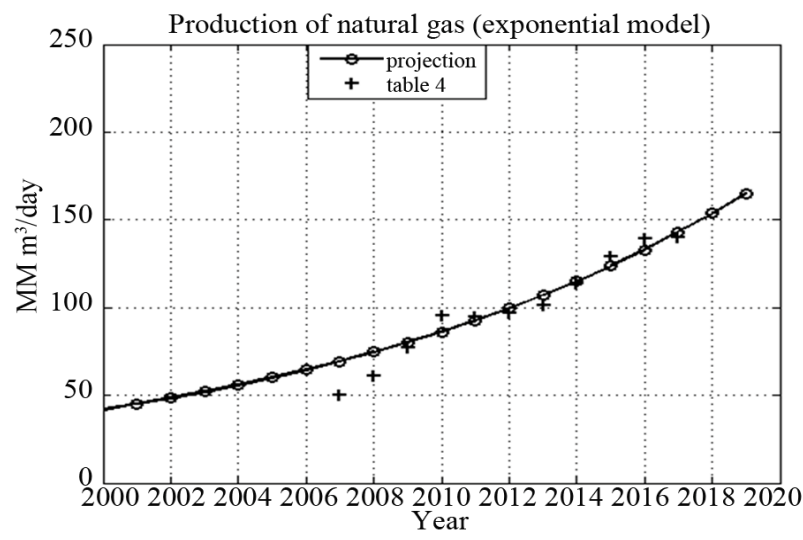

Figure 5. Forecast of the natural gas production in the period 2007 to 2017.

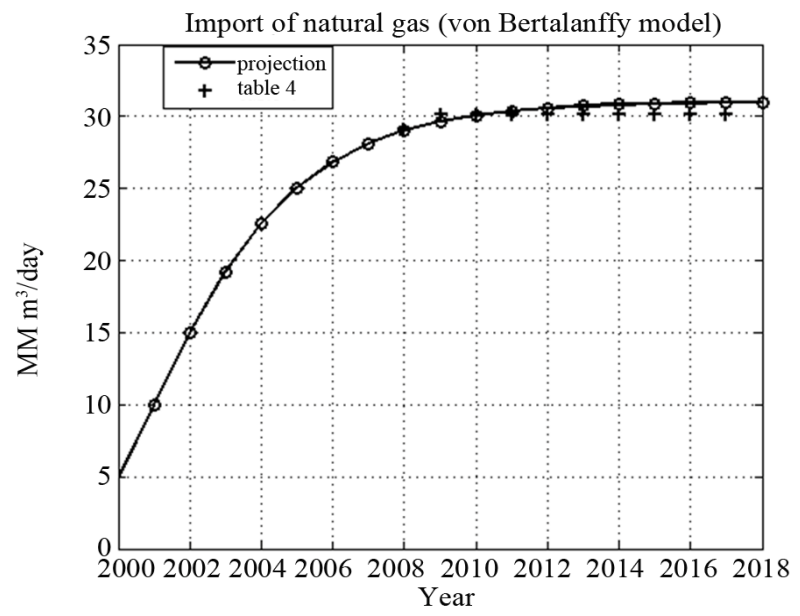

Figure 6. Forecast of the natural gas import for the period from 2007 to 2017.
Table 4. Projection of production and import of natural gas.

\begin{tabular}{ccc}
\hline Year & Production $\left(\mathrm{MM} \mathrm{m}^{3} /\right.$ day $)$ & Import $\left(\mathrm{MM} \mathrm{m}^{3} /\right.$ day $)$ \\
\hline 2007 & 49.766 & 29.1 \\
2008 & 60.971 & 30.1 \\
2009 & 77.475 & 30.1 \\
2010 & 95.354 & 30.1 \\
2011 & 95.015 & 30.1 \\
2012 & 97.164 & 30.1 \\
2013 & 101.509 & 30.1 \\
2014 & 113.696 & 30.1 \\
2015 & 129.240 & 30.1 \\
2016 & 139.501 & 30.1 \\
2017 & 140.144 & 30.1 \\
\hline
\end{tabular}

Source: PDE, 2009.

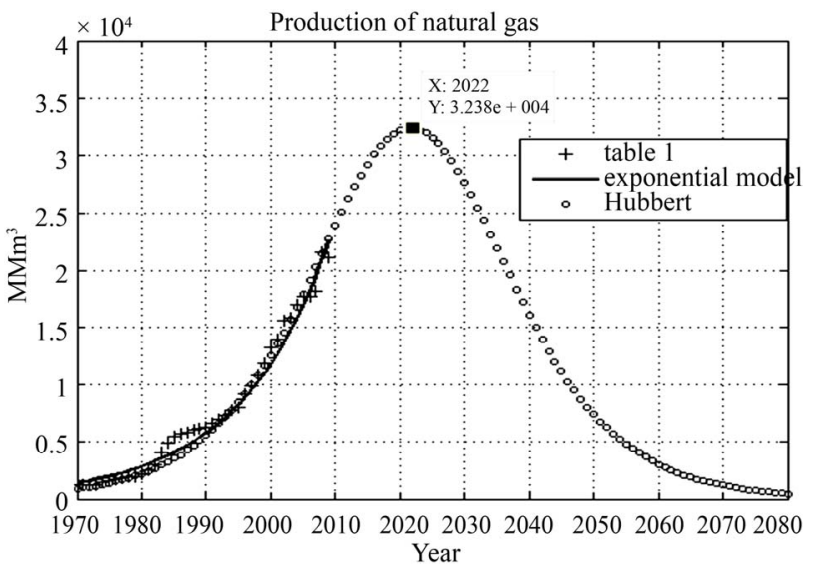

Figure 7. Hubbert curve for Brazilian gas production.

\section{Conclusion}

This study examined the possibility of using biomathematical models in the construction of developments in production, import and consumption of natural gas in Brazil. It was concluded that it isn't appropriate to use only one model to describe the three sets of data involved in this article. In fact each set of data is better described by a certain model. For instance the exponential model is the best one to describe the data of natural gas production, the von Bertalanffy model is the indicated one to describe one data on import of natural gas and finally the logistic model is the best one for describing the data on consumption of natural gas. Therefore, the initial results presented here show that the models used in the study of population dynamics can be used to study the production, consumption and import of natural gas in Brazil.

\section{REFERENCES}

[1] E. B. Tambourgi and S. R. Lourenço, "Gás Natural: Perspectivas e Utilização,” Exacta, Vol. 3, No. 1, 2005, pp. 63-70. 
[2] Energy Information Administration (EIA), “Annual Energy Outlook," 2008. http://www.eia.gov

[3] P. H. de M. Santana, G. de M. Jannuzzi and S. V. Bajay, "Developing Competition while Building up the Infructure of Brazilian Gas Industry,” Energy Policy, Vol. 37, No. 1, 2009, pp. 308-317. doi:10.1016/j.enpol.2008.09.044

[4] N. Apergis and J. E. Payne, "Natural Gas Consumption and Economic Growth: A Panel Investigation of 67 Countries,” Applied Energy, Vol. 87, No. 8, 2010, pp. 2759-2763. doi:10.1016/j.apenergy.2010.01.002

[5] R. C. Bassanezi, "Teaching and Learning with Mathematical Model,” Contexto, São Paulo City, 2006.

[6] M. Rafikov, J. M. Balthazar and H. F. von Bremen, "Mathematical Modeling and Control of Population Systems: Applications in Biological Pest Control,” Applied Mathematics and Computation, Vol. 200, No. 2, 2008, pp. 557-573. doi:10.1016/j.amc.2007.11.036

[7] J. Scarpim, "Modelo de von Bertalanffy Generalizado Aplicado à Curvas de Crescimento Animal," Master's Thesis, Unicamp, Campinas, 2008.

[8] D. G. Zill, “Differential Equations,” Contexto, São Paulo City, 2003.

[9] M. Forouzanfar, A. Doustmohammadi, M. B. Menhaj and S. Hasanzadeh, "Modeling and Estimation of the Natural Gas Consumption for Residential and Commercial Sectors in Iran,” Applied Energy, Vol. 87, No. 1, 2010, pp. 268-274. doi:10.1016/j.apenergy.2009.07.008

[10] A. Tsoularis and J. Wallace, "Analysis of Logistic Growth Models,” Mathematical Biosciences, Vol. 179, No. 1, 2002, pp. 21-55.

\section{doi:10.1016/S0025-5564(02)00096-2}

[11] M. K. Hubbert, "Nuclear Energy and the Fossil Fuels," Drilling and Production Practice, Vol. 95, 1956, pp. 1-57.

[12] J. H. Laherrère, "World Oil Supply-What Goes Up Must Come down, but When Will It Peak?” Oil \& Gas Journal, Vol. 97, No. 5, 1999, pp. 57-65.

[13] Ministry of Mines and Energy (MME), "National Energy Balance,” Energy Research Company, Brasília, 2010.

[14] Energy Research Company, "Ten-Year Plan for Expansion of Energy,” Energy Research Company, Brasília, 2009.

[15] M. R. V. Schwob, M. Henriques Jr. and A. Szklo, “Technical Potential for Developing Natural Gas Use in the Brazilian Red Ceramic Industry,” Applied Energy, Vol. 86, No. 9, 2009, pp. 1524-1531. doi:10.1016/j.apenergy.2008.10.013

[16] J. Siemek, S. Nagy and S. Rychlicki, "Estimation of Natural-Gas Consumption in Poland Based on the Logistic-Curve Interpretation,” Applied Energy, Vol. 75, No. 1-2, 2003, pp. 1-7. doi:10.1016/S0306-2619(03)00013-8

[17] H. Sarak and A. Satman, "The Degree-Day Method to Estimate the Residential Heating Natural Gas Consumption in Turkey: A Case Study,” Energy, Vol. 28, No. 9, 2003, pp. 929-939. doi:10.1016/S0360-5442(03)00035-5

[18] M. Aydinalp, V. I. Ugursal and A. S. Fung, "Modelling of Residential Energy Consumption at the National Level," International Journal of Energy Research, Vol. 27, No. 4, 2003, pp. 441-453. 